\title{
Clashes of Conciseness and Wordiness between English and Persian Verbs
}

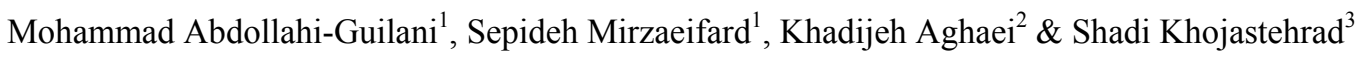 \\ ${ }^{1}$ School of Language Studies and Linguistics, Faculty of Social Science and Humanities, Universiti Kebangsaan \\ Malaysia, Malaysia \\ 2 Islamic Azad University, Gonbad Kavoos Branch, Iran \\ ${ }^{3}$ Faculty of Modern Languages \& Communication, University Putra Malaysia, Malaysia \\ Correspondence: Mohammad Abdollahi-Guilani, School of Language Studies and Linguistics, Faculty of Social \\ Science and Humanities, Universiti Kebangsaan Malaysia. Tel: 98-91-1333-2532. E-mail: \\ abdollahi20@gmail.com
}

Received: March 10, 2012

Accepted: April 17, 2012 Published: August 1, 2012

doi:10.5539/ass.v8n10p118

URL: http://dx.doi.org/10.5539/ass.v8n10p118

\begin{abstract}
This study compares verbs and verb collocation patterns in English and Persian in terms of their internal size. English is a language of conciseness, while Persian uses too many words to express a single concept. Due to the diversity of English verb types governed by certain syntactic restriction rules, and thanks to different types of verb collocations, it is potentially hard for the Iranian EFL learners to establish compatibility between Persian and English verbs. The study, using the Hamshahri Newspaper corpus shows that some English verbs have subject or object arguments and even adverbs included within their semantic and syntactic properties and this makes it very easy for the native speakers to express the most with the least number of words This, however, can make finding equivalents very hard especially when Persian follows an SOV sentence pattern in which the two parts of collocation may stay far from each other.
\end{abstract}

Keywords: concise, Hamshahri corpus, topicalization, valency, verb collocation, verb types, wordy

\section{Introduction}

If a comparison is going to be made between vocabulary and grammar, the best one can be found in the sentence, "Grammar rules do not tell you what to say. Grammar rules tell you how to say something correctly" (Pollock (1997:5). It is the word that is the heart of language and makes events sensible. As Wilkins put it, "Without vocabulary nothing can be conveyed" (1972, p.111). The choice of proper words in the appropriate situation demands a good knowledge of vocabulary domain to make speech natural and sensible.

One of the features of the Persian language is the lengthy size of the sentences. It sometimes happens that a sentence is four lines long. This can give rise to certain problems: first, the listener / reader cannot come to an immediate conclusion until the sentence is wrapped up by the verb, while in English, the reader /listener can almost immediately determine what the message is going to be, because the verb that usually bears the main message is mentioned after the subject (in comparison to Persian). Second, the speaker/ writer falls short of what he is saying / writing and so it happens that he forgets what verb he should use especially when it comes to verb collocations and the verbs accompanied by prepositions.

When writing or speaking in English, the Iranian students fail to observe the principles of end-focus and end-weight (Greenbaum\& Nelson, 2002). Persian writing style requires a long introduction, while English normally has a short one followed by the important points in the body paragraphs. The students' translations from Persian into English show that they misplace different parts of speech; they often have run-on sentences and comma splices. Passive voice that is the common style of most formal writings is hardly seen in the students' academic papers. The choice of vocabulary according to the appropriate register requires more attention in paper writing. 
However, it should be considered that complex structures may not always imply greater syntactic maturity, but may sometimes be the result of an inability to use a concise verb phrase or various linguistic devices such as compounding or formulaic constructions or just verbosity (Fillmore, 1979; Nippold, 1998; Romaine, 1984).

This paper aims to describe and compare the phenomena of wordiness and conciseness in English and Persian. In doing so, it will address the issue of verb collocations in Persian and compare them with the corresponding counterparts in English.

\section{An Overview of Vocabulary Studies}

Reading comprehension relies upon the meaning the readers give to the words. The more vocabulary items the students know, the better they are able to comprehend. Researchers have stated that vocabulary deficiency is a primary cause of academic failure in grades 3 through 12 (Baumann \&Kameenui 2004; Stanovich, 1993). These researchers profess that direct and explicit instruction of a set number of vocabulary words will improve academic success in all content areas. There is increasing evidence that direct vocabulary learning is important even for advanced students because of significant differences between native speakers and advanced learners in noticing, guessing ability, the guessing retention link, and cumulative gain (Laufer, 2003). Laufer (2001) reports that reading supplemented with direct vocabulary learning activities can lead to better results than reading alone.

Knowing the words in a piece of discourse facilitates understanding, which in turn allows the grammatical patterning to become more transparent (Ellis 1999). In addition, it is possible to communicate very effectively with imperfect grammar if the correct vocabulary is known, indeed research suggests that lexical errors impede comprehension more than grammatical errors and that a native-speaker judges rated lexical errors as more serious (Ellis 1995). On a very practical note, Nation (2001) suggests that the 2000 most frequent words are essential for any real language use. Children who enter with limited vocabulary knowledge grow much more discrepant over time from their peers who have rich vocabulary knowledge (Simmons \&Kameenui, 1990).

One of the distinctions between ordinary writing and academic writing lie in conciseness that appears not only in the construction of the sentences and paragraphs, but in the shape of the words as well. There are words that are unnecessarily decorated with objects, adverbs, prepositional phrases etc. This redundancy prevents the naturalness of communication. I believe this issue should be deeply and comparatively discussed in the Iranian EFL context.

\section{Methodology}

This research tries to compare and contrast English and Persian verbs and verb collocations and identify the shortcomings that can give rise to misunderstanding or lack of fluency in communication. The materials that were used for the study included the corpus of Hamshahri Newspaper published in Iran from 1996 to 2007. This corpus contains over three million words in different subjects.This source was a good collection of original materials and helped identify the Persian delexical verbs and their pre-verbs. With the help of the AntConc 3.2.3 software (Anthony, 2007), the Persian delexical verbs were extracted.

\section{Verb Morphology}

English is an SVO language; that is, a declarative sentence starts with the subject followed by verbs and objects, while Persian is an SOV language, so verbs occupy the most final position in a sentence. In Persian, verb forms are more complicated. For the present tense, the imperative root of the infinitive is first separated (e.g., XORDAN (i.e. to eat) $\rightarrow$ XOR (i.e. Eat) and then a clitic is prefixed to the root. A clitic is a type of morpheme with no independent application, but like the affixes, it is attached to a word and unlike them, it is not part of the word. The clitic that is attached to the beginning of the root is called proclictic (Kalbassi 2005). Clitics are in two types: the first one is called proclictic which is prefixed to a root, especially verbs, to denote the aspect of the verb.In Persian, there are two proclitics: 'MI' and 'BI'; the former is used in indicative moods and the latter is for subjunctive aspects. The other type is called enclitic. This one is attached to the end of the word to denote number and subject pronoun (Abdollahi-Guilani, 2012).

\subsection{Formation and Structure}

English has different strategies to make new simple verbs: affixation, conversion, compounding, back formation, and even proper names and names of animals and things. On the contrary, Persian is comparably limited in this respect. Only two or three affixes are employed to make new simple verbs. However, the system of verb collocation is very productive; it is possible to use a delexical verb almost anywhere to collocate with nouns or adjectives to make new verbs. However, in terms of simple verbs, Persian is so weak. With respect to structure, the English verbs are in four groups: 
1) Simple verbs (e.g., go), 2) Derivative verbs (e.g., modernize), 3) Compound verbs (e.g., daydream), 4) Composite (e.g., catch fire, look for, cut down, let fly)

However, Persian verbs can be put into five groups:

1) Simple verbs: (e.g., XORDAN (i.e. eat))

2) Compound verbs consist of nouns or adjectives plus delexcial verbs: ZARBEH XORDAN (i.e. be hit).

3) Prepositional verbs are composed of a preposition and a verb: DAR (i.e. in) + OFTADAN (i.e. fall) $\rightarrow$ DAROFTADAN (i.e. struggle)

4) Compound prepositional verbs are made up of three parts: an independent word, a preposition, and a simple verb: TAN (i.e. body) + DAR (i.e. in) + DAADAN (i.e. give) $\rightarrow$ TAN DAR DAADAN (i.e. surrender; give in)

5) Complex compound verbs are in two structures:

a) apreposition + a content morpheme + a simple verb (See example (a) below).

b) apreposition + noun + preposition + verb (See example (b) below). The meaning of the whole verb cannot be detected from the meaning of the individual constituents:

a)

$\mathrm{AZ}$

CHEM

from

OFTADAN $\rightarrow$ AZ CHESH MOFTADAN

fall

(be looked down upon)

b)

AZ PA DAR AMADAN $\rightarrow$ AZPADARAMADAN

fromfoot in come (fail; collapse)

\subsection{Applications}

The relation between English and Persian simple verbs is not always a one-to-one correspondence. That is to say, they cannot easily find their corresponding verbs. In English, there are some thousand simple verbs while in Persian there are about 300 common simple verbs. So an Iranian EFL learner can only find a one-to-one equivalent for just 300 verbs, and the remaining thousands of English verbs are left without any single-word equivalents in Persian. Thus, he has to make resort to collocations to meet the needs.

\subsection{Simple Verbs v. Collocations}

In addition to the simple verbs, English has its own verb collocations for the many concepts that are also expressed by simple verbs. Again, there should be another attempt in Persian to match English and Persian collocations, which is not so easy, because the delexical verbs that are used in English and Persian are not always fully equivalent. For example, the delexical verb in such collocations as go missing, turn green, grow old, get

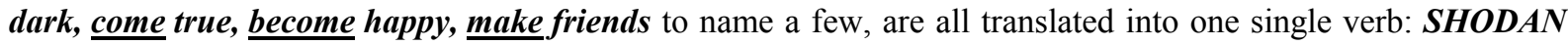
(i.e. become).

In fact, the use of collocations in English mostly seems to be a matter of strategy rather than necessity (Abdollahi-Guilani, 2012).In English, a verb collocation can be used for several reasons:

a) toparaphrase a verb; for example, the verb 'err' can be replaced by 'make amistake'.

b) to change register; instead of the verb 'murder', the collocation 'commit / make amurder' can be used.

c) to describe a noun; the noun is the focus in a collocation and can be modified:

He committed a cold-blooded murder. or The murderthat was committed in that area was very unusual.

On the contrary, since Persian does not have a sufficient number of simple verbs to convey meanings, it is 'obligated' to make use of collocational verbs. Hence, collocation in Persian is a matter of necessity rather than strategy.

\subsection{Verb Properties}

English and Persian verbs differ from each other with respect to transitivity, position of objects, verb-preposition relation, type of arguments, and adverb-latency.

\subsubsection{Transitivity}

English and Persian verbs can be transitive and intransitive, but there is some flexibility in English in terms of their application. 


\subsubsection{Transitivity Verb-shift}

In English, the verb-shift from transitive to intransitive is a syntactic alternation; that is a certain verb can often be used both transitively and intransitively, which is realized by the presence or absence of an object (examples (a-b) below):

a) I am growing plants.

b) The plants are growing.

Some verbs can be contextually considered transitive even if there is not an obvious object (e.g., sentence (c) below):

c) A: What are you doing with the plants, growing or removing them?

B: Growing.

In Persian, however, depending on the type of the verb, the rules may be different:

1) If the verb belongs to the group of simple verbs, it can be replaced by its intransitive/ transitive corresponding verb if available:

MORDAN (i.e. die) v. KOSHTAN (i.e. kill)

2) In Persian, there are very few ambitransitive simple verbs (e.g., POXTAN (i.e. cook), SHEKASTAN (i.e. break), so a Persian verb usually has to undergo morphological transformation to convert to other forms of transitivity. The English verb 'escalate', for instance, is an ambitransitive verb. When it is transitive, it means 'make bad' and when it is intransitive, it means 'become bad'. What happens in English is just a syntactic alternation. In fact, the capacity of a verb to be used both transitively and intransitively is a matter of lexical idiosyncrasy in English (Levin, 2010). The Persian verb lexicon is filled mostly with verb collocations and most of them have to undergo a morphological transformation (Abdollahi-Guilani, 2012). It means the delexical verb has to be replaced by another verb. Hence, for the verb 'escalate' two delexical verbs are used: VAXIM

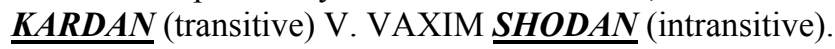

\subsubsection{Intransitive Expansion}

In a pattern labeled reaction-object construction, Levin (1993:97-98) lists a series of intransitive verbs that are followed by cognate objects or semantically related nouns, for example:

1-a) She smiled.

1-b) She smiled her thanks.

2-a) She mumbled.

2-b) She mumbled her adoration.

In neither case (above) can Persian have a similar structure. What, in fact, Persian utilizes to express such concepts is transforming the verbs into adverbs and the nouns / objects into verbs as in (1-c and 2-c) below:

$1-c)$

OO $\underline{\boldsymbol{B} A \boldsymbol{A} \boldsymbol{X} \boldsymbol{X} \boldsymbol{N} \boldsymbol{N} \boldsymbol{E} \boldsymbol{H}}$ TASHAKORKARD

shewith smile thanked

'She thanked with a smile.'

Or in a more expanded version, some other verbs are employed:

\section{OO BA XANDEH TASHAKORATASH RA BAYAAN KARD}

she with smile her thanks

obj. Marker expressed

'She expressed her thanks with a smile'

2-c)

OO $\underline{\boldsymbol{Z I R}-\boldsymbol{e} \boldsymbol{L A} \boldsymbol{A} \boldsymbol{B}}$ TAHSINKARD.

She under lip admired

'She admired [somebody] under lips.' 
The verbs denoting manners of speaking and gestures of emotions can be expanded into such sentences as she thanked [somebody] by smiling and she admired [somebody] by mumbling. Therefore, Persian has to make recourse to lengthy structures to convey the message.

Even adjectives that can be used after certain verb-object construction cannot be paraphrased in Persian unless an adverb is employed. The sentence 'He pushed the door open.' can be expressed by:

\section{OO BAA HOLDADAN DAR \\ RA \\ BAAZKARD.}

$\mathrm{He} \quad$ by pushing

door obj.Marker opened

'He opened the door by pushing.'

\subsubsection{Topicalization}

Some English transitive verbs can have their objects topicalized without any syntactic or morphological changes on the verb, but a preposition is added to show the source of the action; the verb 'radiate' is an example:

a) The sun radiates heat.

b) Heat radiates from the sun.

In Persian, such an application is not possible; in fact, if a single equivalent is supposed to be used for the same

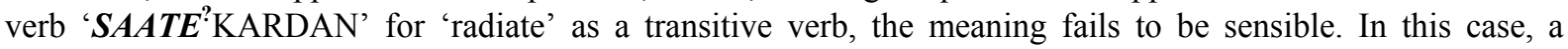
morphological transformation is required to replace $K \boldsymbol{A R D A N}$ (i.e. do) with $\boldsymbol{S H O D A N}$ (i.e. become). In addition, a preposition should be inserted and the verb will be converted to passive voice, too:

a) XORSHID GARMA

SAATE? MIKONAD.

Sun heat radiation does

'The sun radiates heat.'

b)GARMA $\underline{\boldsymbol{A Z}} \quad$ XORSHID

Heat

from sun

SAATE? ${ }^{\text {MISHAVAD }}$.

radiation

becomes

'Heat is radiated from the sun.'

\subsubsection{Verbs with Hidden Objects}

Some verbs in English do not need to have an object explicitly introduced; in fact, there is an understood object in them. For example, the verb 'floss' (i.e. clean between teeth using floss) taken from Levin (1993) is an example:

a) She flossed her teeth.

b) She flossed.

However, Persian does not follow such a system at all. In Persian, for such examples as (b) above, there should be a description like:

\begin{tabular}{lrrr} 
OO $\underline{\boldsymbol{B} A \boldsymbol{A} A \boldsymbol{A}-\boldsymbol{e} \boldsymbol{D A N D A A N}}$ & DANDAANASH & RA & \multicolumn{2}{c}{ TAMIZKARD. } \\
She $\underline{\text { withthread tooth }}$ & her tooth & obj.Marker cleaned
\end{tabular}

'She cleaned her teeth with a dental floss.'

If the second example (b) above is going to be expressed in Persian without mentioning 'her teeth', there should be another verb plus an object indicating the instrument:

$\begin{array}{ccccc}\text { OO } & \text { AZ } & \text { NAX-e } & \text { DANDAAN } & \text { ESTEFADEHKARD. } \\ \text { She } & \text { from } & \text { thread } & \text { tooth } & \text { used }\end{array}$

'She used the dental floss.'

However, outside the context, this sentence can be differently interpreted, too; for example, she used the thread for sewing or something.

A similar item is the verb with an understood reflexive object. The verb 'preen', for example means 'clean oneself with one's beak. In English, there are two choices with this verb: one is to use a reflexive pronoun to refer back to the subject, and the other is an arrangement of the subject and the verb alone:

a) The bird preened itself.

b) The bird preened. 
In Persian, it is necessary to use a verb collocation to express the meaning of preen because there is no single correspondence for it; hence, TAMIZKARDAN BAA MENQAAR (i.e. clean with the beak). On the other hand, there should be an insertion of a reflexive pronoun because clean is a transitive verb and so it requires an object. Therefore, sentences ( $a-b)$ are identically translated into the following:
c) PARANDE
BAA MENQAR
XODASH
RA
TAMIZKARD.
bird
with beak
itself
obj.Marker
cleaned

'The bird cleaned itself with its beak.'

\subsubsection{Verbs with Latent Adverbs}

Some English verbs, as Levin (1993:4) pointed out, are "verbs of directed motion, describing an object moving and simultaneously emitting a sound, as in The bullet whistled through the window. Persian does not have such a structure. In fact, Persian uses a lengthy structure consisting of an adverb or a reduced relative clause plus an ordinary verb to express the meaning:

\section{GOLOOLEH SOOTZANAAN AZMIAN PANJEREH OBOORKARD}

bulletwhile whistling through window passed

'The bullet passed through the window, whistling.'

In English, some verbs have a latent adverb in them. For example, 'grab' means Get hold of or seize quickly and easily. The adverbs quickly and easily are within the verb, but for most Persian verbs, a separate adverb is usually needed to give a secondary layer of meaning to the verb.

Unlike many English verbs that have an understood adverb or prepositional phrase with them, many verbs in Persian are adjunct-imposed; that is to say, they have to have an adverb or a prepositional phrase accompany a verb to express the English intention. For example, 'cane' is a concise verb that means 'beat with a cane' while in Persian this idea should be expressed with a general verb like ' $\boldsymbol{Z} \boldsymbol{A D} \boldsymbol{A} \boldsymbol{N}$ ' (i.e. beat) plus an adverb or a prepositional phrase, in this case 'BAA ASAA' (i.e. with a cane).

Itis noteworthy that some thousand verbs in Persian are collocationally constructed and so the issue turns to be more complicated when an adverb or prepositional phrase has to accompany the collocates. For the purpose of accuracy and fluency, it is better to be concise instead of being unnecessarily wordy.

\subsubsection{Verbs with Prepositions}

All Persian verb-noun collocations that make transitive and especially ditransitive verbs need either prepositions in front of the object or a direct object marker (i.e. 'RA' in Persian) after the object. This, in turn, makes it hard for the Iranian EFL learner to find appropriate equivalents because in cases where a verb may need a preposition in Persian, English will not use one (as in 'attack' versus 'HAMLEH KARDAN BE', which requires the preposition ' $\boldsymbol{B} \boldsymbol{E}$ ') or if a preposition is employed in both languages, there may be different equivalents in similar cases and even the place of the prepositions accompanying the beneficiary or benefit objects may be different from verb to verb.

Some English verbs usually in the category of eating and ingesting like chew, chomp, crunch, gnaw, lick, munch, are arbitrarily used with a preposition ( usually 'at' or 'on') without any change in meaning and so are the location verbs climb and descend which can be arbitrarily used with the prepositions up and down (Levin, 1993:42):

a) The mouse nibbled (at/on) the cheese.

b) He climbed (up) the mountain

c) He descended (down) the stairs.

In Persian, it is not usually allowed for verbs to have an arbitrary preposition. In fact, when a preposition is employed, there must follow an object or a location.

\subsubsection{Argument-bound Verbs}

Unlike Persian verbs, many English verbs are argument-type restricted. It means the verb can only be used with a certain argument whether subject or object. For example, the verb burp (i.e. expel gas from stomach) can be intransitively used for any animate subject argument (examples a-b below) but in the transitive application, its object argument is limited to babies (e.g., a-c below). As the example taken from Levin (1993:32) shows sentence (d) is unacceptable: 
a) The baby burped.

b) The doctor burped.

c) I burped the baby.

d)* I burped the doctor.

A second type of bound argument is the use of there- expletive. In English, it is very common to insert the expletive there before certain verbs denoting existence, appearance, or motions at a direction specified (Levin, 1993), but in Persian, there is just one equivalent for 'there + be' (VOOJOOD DAASHTAN or MOJOOD BOODAN (i.e. exist). Other constructions with different verbs do not exist in Persian. Therefore, among the following pragmatically different pair examples, Persian employs the (a)'s, except for number 1 where both choices are acceptable.

1. a) A pen is on the table.

b) There is a pen on the table.

2. a) A ship appeared on the horizon.

b) There appeared a ship on the horizon.

3. a) A little boy darted into the room.

b) There darted into the room a little boy.

4. a) A problem developed.

b) There developed a problem.

A third type of bound-argument can be found in the use of dummy-it subject. In English, it is possible to start a sentence with dummy-it with weather verbs or structures having adjectives followed by infinitives like the following:

a) It is easy to learn English.

b) It seems that they are coming.

c) It stands to reason that she will do the job.

d) It is going to rain.

e) It takes two hours to reach there.

f) I feel it necessary to make my father proud of me.

Persian, on the contrary, cannot start a sentence like the above-mentioned structures. It needs to put a 'real' subject such as a noun or noun-substitutes to begin a sentence.

\section{Discussion}

Among the different characteristics of a good writing, five principles can be considered pivotal: clarity, accuracy, conciseness, accessibility, and correctness (CACAC). For the purpose of this paper, conciseness can be roughly defined as achieving both clarity and accuracy in as few words as possible, so it means expressing as much as possible without being redundant.

Contrary to what inexperienced writers often think, a writing style that is pretentious, wordy, or otherwise unnecessarily complicated, does not contribute to making the author appear more expert on the subject: an easier-to-understand paper gives its author far more credit (Turk, 1978). For the present discussion, English verbs can be comparatively discussed in seven groups.

1. In Group One, English and Persian simple verbs can be classified into the following:

a) English possesses a great number of simple verbs while Persian verbs are very limited in number:

English: go

Persian: RAFTAN (i.e. go)

b) A simple verb in English may find its equivalent in a verb collocation in Persian:

English: watch

Persian: Preverb + delexical verb $\rightarrow$ TAMAASHA KARDAN (i.e. sight + do). 
c) The names of living beings including humans and animals can also be used as verbs in English, while Persian does not have this property:

English: Pasteur

Persian: Preverb + delexical verb $\rightarrow$ PASTORIZEH KARDAN (i.e. pasteurization + do)

English: fish

Persian: Preverb + delexical verb $\rightarrow$ MAHI GEREFTAN (i.e. fish + catch)

d) English can make use of non-living things as verbs, but Persian lacks such a feature.

English: berry

Persian: Preverb + delexical verb $\rightarrow$ TOOT CHIDAN (i.e. berry + pick)

e) English simple verbs may find their Persian equivalents in a verb collocation pattern, for example, the verbs 'hand' and 'cane' need a verb collocation plus a prepositional phrase:

English: hand

Persian: Verb collocation + prepositional phrase $\rightarrow$ BAA DAST DAADAN (i.e. give by hand)

English: cane

Persian: Verb collocation + prepositional phrase $\rightarrow$ BAA ASSA ZADAN (i.e. hit with a cane)

2. In Group Two, there is a transitive simple verb followed by an object and an adjective. In Persian, however, there is not such a one-to-one correspondence. In fact, the verb has to be analyzed first and then a prepositional phrase (whether with a noun or gerund) should be used to define the internal meaning of the English verb:

The dog barked my mother awake

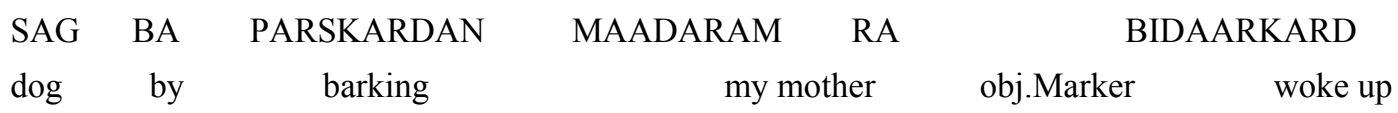

'The dog woke up my mother by barking.'

Or two sentences are mixed to convey the meaning

$\begin{array}{lcrrrr}\text { SAG } & \text { PARSKARD } & \text { VA } & \text { MAADARAM } & \text { BIDAARSHOD } \\ \operatorname{dog} & \text { barked } & & \text { and my mother } & \text { woke up / was woken }\end{array}$

'The dog barked and my mother woke up / was woken.'

A nominalization format may also express the meaning in one sentence:

PARS-e SAG MAADARAM RA BIDAARKARD

bark of dog my mother obj.Marker woke up

'The barking of the dog / the dog's bark woke up my mother.'

As another example, the verb kick can be similarly used:

She kicked herself free.

OO BA LAGAD ZADAN XODASH RA AZAAD KARD

She by leg hitting herself obj.Marker free did

'She freed herself by kicking.'

or

OO LAGAD ZAD VA XODASH RA AZAAD KARD

She leg hit and herself obj.Marker free did

'She kicked and made herself free.'

In fact, in Persian, the adjective turns into a verb collocation. For all of the examples below, Persian uses long structures either verb collocation (which is itself a wordier verb phrase than the English concise simple verb is) with a prepositional phrase or it resorts to using two clauses (taken from Levin, 2008: 17):

He pounded the metal flat.

The jogger ran the pavement thin 
The jogger ran his sneakers threadbare.

She danced herself stiff

She sang herself hoarse.

3. In Group Three, although there is a similar structure to Group Two, Persian has only one choice. The type of the verb (e.g., freeze, burn, swing, steam, boil, bang, creak, rumble, thud etc. taken from Levin, 2008) may determine which structure can be applied. These verbs mostly refer to states and resultant events rather than real and eventive actions:

freeze :The pond froze solid

In Persian, a sentence like this is put in the format of two clauses:

HOZCHEH YAX BASTVA SEFT SHOD

pond ice formed and solid became

'The pond froze and became solid.'

roll: The curtain rolled open

PARDEH ROLL XORD VA BAAZ SHOD.

curtain roll ate and open became

'The curtain rolled and opened.'

As can be seen, all the English simple verbs are converted to verb collocations in Persian and all the adjectives become part of a verb collocation. This kind of transformation makes the structure of the sentence lengthy and hence the time span used for transferring the idea will become longer. In the following examples, Persian uses the second column to convey the idea:

1. break: The bottle broke open.

v. The bottle broke and opened

2. burn: The food burned black.

v. The food burned and turned black.

3. steam: Our damp clothes steamed dry on the radiator v. Our wet clothes steamed on the radiator and dried.

4. boil: the kettle boiled dry. $\quad$ v. The kettle burned. OR The water of the kettle became dry.

5. swing: The gate swung shut. $\quad$ v. The gate swung and closed/got closed.

6. bang: The trapdoor banged shut. $\quad$ v. The trap shut noisily / The trap made a loud sound and shut.

For sentence (2), there is an equivalent free from a double-clause construction (although a verb collocation), but it is used in informal Persian:

GHAZAA JEZGHAALEH SHOD

food fully burned became

For sentence (4), Persian does not use the verb 'boil', because it may take it for granted that a kettle is for water, so it just mentions the result (i.e. burning).

For sentence (6) and even with verbs denoting sounds (e.g., thud, creak, rumble etc.), Persian seems to have two choices. One is to use an adverb of manner and the other is making use of a second clause.

4. In Group Four, English simple verbs are followed by an object, preposition, and a location name. In this pattern, the action of the subject affects the object and causes dislocation of the object. Take the example below:

He sneezed the tissue off the table.

This sentence means the tissue was dislocated due to the sneeze. This structure may look like the sentence 'He sent the letter to him.' The difference, however, is that in the latter sentence, there is an intention in the instigator of the verb, while in this pattern, there is no predetermined program. In Persian, sentences like this cannot easily find their correspondences:

She coughed the foam off the coffee

OO SORFEH KARD VA KAF-e GHAHVEH RIXT.

she cough did and foam coffee fell

'She coughed and the foam of the coffee fell off.' 
There are three points here. The first one is the use of verb collocation in place of the English simple verb, the second one is that in Persian, there are two clauses and finally in Persian the resultant event is explicitly expressed. Considering all, the issue of English conciseness and Persian wordiness can clearly be observed here. Still, this sentence can be stated by using a prepositional phrase:

OO KAF-e GHAHVEH RA

\section{BA SORFEHKARDAN RIXT.}

she foam coffee Obj. Marker by coughing dropped

'She dropped the foam of the coffee by coughing.'

There is some point to mention here. In such a rendition, the emphasis of the messages is transposed from 'cough' to 'drop'. The original message says that the cough was the main action, while in this translation, coughing is just a manner of the action. Hence, it can be concluded that the person 'intended' to drop the foam and so she did it by coughing. It is worth noting that the verb RIXT used in both translations above is an ambitransitive verb; that is, it is both transitive and intransitive, so in the former sentence, it serves as an intransitive verb, while in the latter it functions as a transitive one.

5. In Group Five, the English verb denotes a change of state + motion / sound emission. In this group, verbs of sound may show directed motion. This structure is available when the emitter is construable as self-energetic, with the sound being a necessary concomitant of its motion so sentences (c \& d) are not correct (Hale \& Keyser, 1997):

a. The truck rumbled/shrieked into the driveway.

b. The bullet whistled over his shoulder.

c. ${ }^{*}$ The shoes squeaked into the room.

d. * The reversing truck beeped into the driveway.

In Persian, sound verbs do not serve as event verbs showing other functions except for which they are entitled, i.e. showing a type of sound. Therefore, for an Iranian EFL learner, translating such verbs means inserting a second verb that is suggestive of motion plus an adverb describing the type of the sound. So sentences (a \& b) can be rewritten as:

KAMION BAA SEDAYE ARRAM / SHADID VAARED-e truck with sound low / high enter driveway became

'The tuck entered the driveway in a low / high sound.'

There are four points worth mentioning. First, the original verb cannot be translated into its simple verb counterpart in Persian. Second, the verb is transformed into adverbs of manner or prepositional phrases. Third, since the preposition 'into' suggests 'coming', any verb denoting coming can be used. Fourth, the verb collocation used in Persian 'VAARED SHOD' has been intervened by the location name 'driveway' So this splits the Persian verb collocation and creates a distance and if the location name were a long one, the gap would be wider. If a synonymous verb such as AAMAD (i.e. came) were used, a preposition would be needed. It would again stand before the location name and make a gap, too. All these suggest a wordy structure in Persian verbs.

The following examples also confirm the conciseness of English verbs and the wordiness of Persian ones.

The branding iron burned into the calf's skin. (Croft 1991:161, (25))

The mother rocked the baby to sleep. (Levin \&Hovav, ONLINE)

The chocolate melted into the sofa.

They danced out of the room.

The police shot the thief to death.

6. In Group Six, some English verbs show alternations in terms of the use of prepositions. Take the following sentences:

a) I hit his leg.

b) I hit him on the leg

In English, both sentences can equally be used, but in Persian, only the first one is available. Or in the sentence, 'She went red in the face.' Persian seems not to allow such a structure and instead prefers the following:

SOORATASH SORX SHOD 
her face red became

'She blushed.'

7. In Group Seven, the issue of conflation of event-verbs arise Levin \&Hovav (2008) quote Kiparsky (1997, p.476) as saying, "Simple predicates refer to simple events." It is often assumed that verbs can refer to single happenings. However, a cursory glance at the attested verb meanings reveals that verbs often denote a complex chain of happenings. Levin and Hovav also say that Goldberg (1998) discusses the verb sauté which describes a situation involving heating food with a small amount of fat and simultaneously stirring it. Take the following example,

The boat sailed into the cave.

The event of motion into the cave can be conflated with the event of sailing since sailing causes the motion. The sentence 'The boat burned into the cave.' is impossible because the event of burning cannot cause the event of motion. So the event of motion and the event of burning cannot be expressed in a single verb-headed clause. But it must be expressed periphrastically as in The boat sailed into the cave while burning or the boat burned while going into the cave.

However, in the following, it is possible because the motion and the burning event can be conflated and expressed in a single verb-headed clause:

The branding iron burned into the calf's skin.

In neither case, however, can Persian accommodate the conflation of two events in one verb. Persian, therefore, has to resort to two verbs or rather two clauses to express the above meanings. In the case of 'sail', Persian does not have a verb to denote the concept of navigation that can be headed by an inanimate subject, too. If the subject were the captain, for example, it would make sense. Furthermore, there is a not a verb that exactly expresses the meaning of 'sail'. Instead, such verbs as BORDAN (i.e. take), HEDAAYAT KARDAN (i.e. direct; steer), RAANDAN (i.e. drive), which are general verbs are used to convey the intended meaning (with the animate subject). So the sentence would appear like the following:

$\begin{array}{lccc}\text { GHAYEGH BEDAROON GHAAR RAFT } & \\ \text { boat } & \text { into cave went }\end{array}$

'The boat went into the cave.'

This is a very general interpretation of the sentence and does not include the movement of the boat on the water (maybe it was carried onto a ship into the cave).

OO GHAYEGH RA BEDAROON GHAAR BORD / HEDAAYAT KARD / RAAND.

he boat obj. Marker into boat took / steered / drove

'He took / steered / drove the boat into the cave.'

\section{Conclusion}

After the discovery of ether as an anesthetic substance, physicians needed a term that designated the action of applying ether to patients, and the word 'etherize' was coined (Plag, 2005). Longer phrases and even whole clauses can be substituted by single complex words, which not only makes life easier for speakers and writers, but can also serve to create stylistic variation.

Some languages such as English or Spanish have immensely rich vocabularies. When English speakers want to describe something in English, they have a wide choice of words at their disposal and can say what they want to say in many different ways. For some people, being able to use all of these words is rather too great. Replacing the elongated verb by a one-word action verbinvariably makes the sentence more readable. Iranian EFL learners (and possibly some other nationalities) usually have lengthy passages. It is not their fault. It may be due to the verb system that has no simple verb equivalents for the English concise verb concepts. Following at least one of the five principles of CACAC can help them get their meaning across more easily. What a Persian speaker can lengthily put in three words, his English counterpart can concisely and efficiently write in one word: 'examine' for 'make an examination', 'consider' instead of 'take into consideration' and 'conclude' in place of 'reach a conclusion'.

\section{References}

Abdollahi-Guilani, M. (2012). A comparative analysis of verb collocation patterns in English and Persian: Pedagogical implications. Unpublished PhD Dissertation, UKM, Malaysia.

Anthony, L. (2007). A free text analysis software. Retrieved from http://www.antlab.sci.waseda.ac.jp/ 
Baumann, J. F., \& Kameenui, E. J. (2004). Vocabulary instruction:Research to practice. New York: Guilford Press.

Croft, W. A. (1991). Syntactic categories and grammatical relations. University of Chicago Press, Chicago, IL.

Ellis, N. (1995). Vocabulary acquisition: Psychological perspectives and pedagogical implications. The Language Teacher, 19(2), 12-16.

Ellis, R. (1999). Learning a second language through interaction. Amsterdam: John Benjamins.

Fillmore, C. J. (1979). On fluency. In C. J. Fillmore, D. Kempler \& W. S.-Y. Wang (Eds.), Individual differences in language ability and language behavior (pp. 85-101). New York: Academic Press.

Greenbaum, S., \& Nelson, G. (2002). An introduction to English grammar (2nd ed.). Harlow: Longman.

Hale, K., \& Keyser, J. (1997). On the complex nature of simple predicators. In A. Alsina, J. Bresnan, \& P. Sells (Eds.), Complex predicates (pp. 29-65). CSLI Publications.

Hamshahri Newspaper Corpus. Retrieved from http://ece.ut.ac.ir/dbrg/hamshahri/

Kalbassi, I. (2005). Saaxt-e eshteghaaghivazhedar Farsi emrooz. [The derivational construct of words in modern Persian]. Cultural studies and research center of Iran (Pazhooheshgah): Tehran. Iran

Laufer, B. (2001). Reading, word-focused activities, and incidental vocabulary acquisition in a second language. Prospect, 16, 44-54.

Laufer, B. (2003). Vocabulary acquisition in a second language: Do learners really acquire most vocabulary by reading? Some empirical evidence.The Canadian Modern Language Review, 59, 567-587. http://dx.doi.org/10.3138/cmlr.59.4.567

Levin, B. (1993). English verb classes and alternations: a preliminary investigation. The university of Chicago Press.

Levin, B., \& Hovav, M. R. (2006). Two structures for compositionally derived events. Retrieved from http://www.stanford.edu/ bclevin/salt991rh11.pdf

Levin, B., \& Hovav, M. R. (2008). Reflections on manner/result complementarity. Retrieved from http://www.stanford.edu/ bclevin/jer08oup.pdf

Nation, I. S. P. (2001). Learning vocabulary in another language. Cambridge: Cambridge University Press.

Nippold, M. A. (1998). Later language development: the school-age and adolescent years (2nd ed.). Austin, TX: PRO-ED, Inc.

Plag, I. (2005). Word formation in English. Cambridge University Press.

Pollock C.W. (1997). Communicate what you mean. Printice-Hall, INC.

Radford, A. (2006). Minimalist syntax: Exploring the structure of English. Cambridge University Press.

Romaine, S. (1984). The language of children and adolescents. Oxford: Basil Blackwell.

Stanovich, K. E. (1993). Does reading make you smarter? Literacy and the development of verbal intelligence. Adv Child DevBehav, 24, 133-180. http://dx.doi.org/10.1016/S0065-2407(08)60302-X

Simmons, D. C., \& Kameenui, E. J. (1990). The Effect Of Task Alternatives on Vocabulary Knowledge: A Comparison of Students with and without Learning Disabilities. J Learn Disabil, 23(5), 291-297, 316. http://dx.doi.org/10.1177/002221949002300508

Turk, Ch. (1978). Do you write impressively? Bulletin of the British Ecological Society, 9, 3, 510.

Wilkins, D. (1972). Linguistics in language teaching. Edward Arnold. 